\title{
Cellular Lipid Composition Affects Sensitivity of Plant Pathogens to Fengycin, an Antifungal Compound Produced by Bacillus subtilis Strain CU12
}

\author{
Cody Wise, Justin Falardeau, Ingrid Hagberg, and Tyler J. Avis
}

Department of Chemistry, Carleton University, 1125 Colonel By Drive, Ottawa, Ontario, K1S 5B6, Canada. Accepted for publication 19 March 2014.

\begin{abstract}
Wise, C., Falardeau, J., Hagberg, I., and Avis, T. J. 2014. Cellular lipid composition affects sensitivity of plant pathogens to fengycin, an antifungal compound produced by Bacillus subtilis strain CU12. Phytopathology 104:1036-1041.

Fengycin is an antimicrobial cyclic lipopeptide produced by various Bacillus subtilis strains, including strain CU12. Direct effects of fengycin include membrane pore formation and efflux of cellular contents leading to cell death in sensitive microorganisms. In this study, four plant pathogens were studied in order to elucidate the role of membrane lipids in their relative sensitivity to fengycin. Inhibition of mycelial growth in these pathogens varied considerably. Analysis of membrane lipids in

these microorganisms indicated that sensitivity correlated with low ergosterol content and shorter phospholipid fatty acyl chains. Sensitivity to fengycin also correlated with a lower anionic/zwitterionic phospholipid ratio. Our data suggest that decreased fluidity buffering capacity, as a result of low ergosterol content, and higher intrinsic fluidity afforded by short fatty acyl chain length may increase the sensitivity of microbial membranes to fengycin. Our results also suggest that lower content in anionic phospholipids may increase fengycin insertion into the membrane through reduced electrostatic repulsion with the negatively charged fengycin. The intrinsic membrane lipid composition may contribute, in part, to the observed level of antimicrobial activity of fengycin in various plant pathogens.
\end{abstract}

Synthetic chemical pesticides remain one of the most widely used control measures against plant pathogens. However, synthetic chemicals have major drawbacks, such as the development of resistance in plant pathogens (2). Other synthetic chemicals have adverse effects on human health and the environment (20), leading to the present constraint of few newly registered replacement pesticides for banned chemicals (18). In this context, there remains an urgent need for efficient and reliable measures to control plant pathogens.

An alternative of interest to synthetic chemicals for the control of plant pathogens is the use of biocontrol agents (i.e., beneficial microorganisms with direct or indirect antagonistic activity against these plant pathogens). Biocontrol agents are generally considered safe and ecofriendly alternatives to synthetic chemicals (24,31). In particular, Bacillus subtilis (Ehrenberg) Cohn shows great promise for managing plant pathogens. B. subtilis isolates have been found to produce a wide variety of peptide $(15,24)$ and/or nonpeptide $(17,34)$ antimicrobial compounds. Previous work in our laboratory has identified B. subtilis strain CU12, a microbial antagonist isolated from a crop-growing field with a history of low disease (29).

Among the antimicrobial compounds produced by numerous strains of B. subtilis, including strain CU12, fengycin is of particular interest for the control of fungal plant pathogens. Fengycin is a cyclic lipopeptide containing a $\beta$-hydroxy fatty acyl chain bound to a decapeptide with eight of the amino acids forming a lactone ring structure (15). Interest in fengycin is due to its lower hemolytic activity when compared with other B. subtilis lipopeptides and its strong antifungal capability, specifically against filamentous fungi (12). Fengycin is known to affect the biological

Corresponding author: T. J. Avis; E-mail address: tyler_avis@ carleton.ca

http://dx.doi.org/10.1094/PHYTO-12-13-0336-R

(C) 2014 The American Phytopathological Society membranes of sensitive fungi, causing membrane pore formation and efflux of cellular contents leading to cell death $(12,26)$. The amphiphilic nature and small size of the peptide portion of fengycin may aid in its insertion into the membrane $(10,12)$. At sufficiently high concentrations, fengycin aggregates, leading to the creation of large sustainable pores and a complete efflux of cellular contents $(12,26)$. However, the precise mode of action of fengycin and the intrinsic biochemical determinants implicated in its antifungal activity have not been fully elucidated.

Alternaria solani Sorauer (Ascomycota), Botrytis cinerea Pers. (Ascomycota), Fusarium sambucinum Fuckel (Ascomycota), and Pythium sulcatum R. G. Pratt \& J. E. Mitch. (Oomycota) are fungi or fungus-like microorganisms causing disease in various plants. A. solani causes disease in potato that is commonly known as early blight (23). B. cinerea causes gray mold of numerous crops, including tomato, strawberry, bulb crops, and grape (4). Dry rot and cavity spot are among the most prevalent diseases in potato and carrot, respectively. Dry rot is caused by various species of Fusarium (including F. sambucinum) (9) while cavity spot is caused by different species of Pythium (including $P$. sulcatum) (20).

In order to gain insight into fengycin's mode of action and to ascertain determinants in its mechanisms of activity, these four plant pathogens were assayed to determine (i) sensitivity to fengycin, (ii) intrinsic microbial membrane lipid components and characteristics (sterol content, phospholipid moieties, phospholipid fatty acyl chains), and (iii) correlation of membrane lipid composition with microbial sensitivity to fengycin.

\section{MATERIALS AND METHODS}

Microbial material. B. subtilis strain CU12 was isolated from a disease-suppressive soil in Ottawa, Canada (34) and maintained on tryptic soy agar (TSA) (Becton Dickinson, Sparks, MD). The fungi A. solani, B. cinerea, and F. sambucinum and the oomycete 
$P$. sulcatum were maintained on potato dextrose agar (PDA) (Becton Dickinson). A. solani, B. cinerea, and F. sambucinum were obtained from the Laboratoire de diagnostic en phytoprotection (MAPAQ, Québec, QC, Canada). P. sulcatum was isolated from an infected carrot root and is available at the Canadian Collection of Fungal Cultures (Agriculture and AgriFood Canada, Ottawa, ON, Canada).

Evaluation of microbial sensitivity to fengycin. Fengycin A was isolated and purified from B. subtilis strain CU12 as described previously (1). Fengycin was chromatographically and spectroscopically compared with an authentic fengycin A standard (AIBI, AUG, Belgium) to confirm identity of the compound. Bioassays were performed in liquid culture of potato dextrose broth (PDB) (Becton Dickinson) for the three fungi and in V8 juice broth containing clarified V8 juice at $200 \mathrm{ml} / \mathrm{liter}$ and $\mathrm{CaCO}_{3}$ at $2 \mathrm{~g} /$ liter for $P$. sulcatum. Briefly, bioassays were performed in $1 \mathrm{ml}$ of culture medium and fengycin treatment in sterile microcentrifuge tubes. Final fengycin concentrations tested were 0 (control), 10, 25, 33, 50, 67, 75, 100, 125, and $150 \mu \mathrm{g} / \mathrm{ml}$. A 4-mm agar plug containing actively growing mycelia was transferred to each tube. Growth was measured after $96 \mathrm{~h}$ of incubation with shaking $(180 \mathrm{rpm})$ at $28.5^{\circ} \mathrm{C}$. Mycelial biomass was filtered, washed with sterile water, and lyophilized. Growth was measured as dry weight. Minimum inhibitory concentration (MIC) was defined as the lowest tested fengycin concentration resulting in $100 \%$ inhibition of growth for each microorganism. The experiments were conducted according to complete block designs with three replicates. The experiments were repeated twice.

Extraction of fungal lipids. A. solani, B. cinerea, and $F$. sambucinum were grown in five flasks containing $100 \mathrm{ml}$ of tryptic soy broth (TSB) (Becton Dickinson). P. sulcatum was grown in five flasks containing $100 \mathrm{ml}$ of V8 medium. Each microorganism was grown in triplicate and all flasks were incubated at $28.5^{\circ} \mathrm{C}$ for $96 \mathrm{~h}$ with shaking $(180 \mathrm{rpm})$. The microbial biomass was separated from the media by filtration (Fisher number 8 filter paper) and frozen prior to lyophilization. Lyophilized cells were ground to a powder and extracted with chloroform/methanol/water (100:100:50 ml/g of dry weight). The mixture was protected from light and agitated using a stirring bar $(400 \mathrm{rpm})$ for $3 \mathrm{~h}$ at $23^{\circ} \mathrm{C}$. Following incubation, the solvents containing the extracts were removed by filtration and the biomass was reextracted with chloroform/methanol/water (200:100:50 $\mathrm{ml} / \mathrm{g}$ of dry weight) overnight, as previously described. Following the second incubation, the solvents containing the extracts were removed by filtration and the two extracts were combined. The aqueous fraction was removed by partitioning the extracts against chloroform and water in a separatory funnel. The remaining organic phases containing the lipids were dried using anhydrous $\mathrm{MgSO}_{4}$ (Sigma, Mississauga, ON, Canada) to remove all traces of water. Collected organic phases were evaporated to dryness using a Heidolph 4000 rotary evaporator (Schwabach, Germany). The residues were resuspended in chloroform, transferred to screw-cap tubes, and dried under a stream of nitrogen gas. The resulting oily residue constituted the total lipid extracts. Extracts were resuspended in chloroform and kept at $4^{\circ} \mathrm{C}$ until use.

Separation of lipid classes. Neutral and polar lipids were separated by acetone precipitation. Acetone $(6 \mathrm{ml})$ was added to the dried total lipids. The tubes were vortexed and placed at $-20^{\circ} \mathrm{C}$ for $1 \mathrm{~h}$. The tubes were then centrifuged at 4,500 rpm for $10 \mathrm{~min}$ at $4^{\circ} \mathrm{C}$. The supernatant was recovered and the pellet was resuspended in $1 \mathrm{ml}$ of acetone and the procedure was repeated. The supernatants were combined and evaporated to dryness using a nitrogen drier. The acetone extract constituted the neutral lipid fraction while the dried pellet represented the polar lipid fraction.

Ergosterol analysis. Sterols were obtained from alkaline hydrolysis of the neutral lipids. A 1:10 ratio of $\mathrm{KOH}$ solution (33\% [wt/vol]) and ethanol (95\%), respectively, was added to the total neutral lipids. The tubes were heated to $90^{\circ} \mathrm{C}$ for $2 \mathrm{~h}$. Following heating, the mixture was washed with $5 \mathrm{ml}$ of hexane and the hexane fraction containing the unsaponifiable fraction was recovered. Two subsequent 5-ml washes were performed with hexane. The hexane fractions were combined, evaporated to dryness, and resuspended in a small volume of hexane for further analysis. Ergosterol in the unsaponifiable fraction was quantified on an Agilent 6890 Series gas chromatograph (Mississauga, ON, Canada) coupled with an Agilent 5973 quadropole mass spectrometer using a ZB-5 capillary column $(30 \mathrm{~m}$ by $0.25 \mathrm{~mm}$ i.d. by $0.25 \mu \mathrm{m}$; $5 \%$ phenyl and $95 \%$ dimethyl-polysiloxane) (Phenomenex, Torrance, $\mathrm{CA}$ ) in splitless mode. The temperature program was $100^{\circ} \mathrm{C}$ for $2 \mathrm{~min}$, increased by $20^{\circ} \mathrm{C} \mathrm{m^{-1 }}$ to $200^{\circ} \mathrm{C}$, held for $1 \mathrm{~min}$, increased by $10^{\circ} \mathrm{C} \mathrm{m^{-1 }}$ to $300^{\circ} \mathrm{C}$, and held for $5 \mathrm{~min}$. Sterols were quantified using a calibration curve of an authentic ergosterol standard (Sigma).

Polar lipid analysis. Polar lipids (mainly phospholipids) obtained from acetone precipitation were made up in chloroform and divided into two equal volumes. One portion was used for the quantification of phospholipid classes (polar head groups) and the second half was used for quantification of the phospholipid fatty acids (FAs).

Phospholipid classes. Individual phospholipids were separated by preparative thin layer chromatography (TLC) $(0.5$-mm-thick silica gel on glass-backed plates) (Analtech, Newark, DE) using a solvent system of chloroform/acetone/methanol/acetic acid/water (10:4:2:2:1, by volume). Phospholipid classes were revealed by exposing plates to a minimal amount of iodine vapor. Individual phospholipid classes were identified by comparison of $R_{f}$ values to authentic standards (Sigma). Silica gel containing each identified spot was scraped from the TLC into a clean dry test tube. Bligh-Dyer solution (1:2 ratio of chloroform/methanol, by volume) was added to the silica gel and vortexed for $1 \mathrm{~min}$ before centrifugation $(4,000 \mathrm{rpm}$ for $10 \mathrm{~min})$. Supernatants containing the phospholipids were collected, brought to dryness under a stream of nitrogen gas, and stored at $4{ }^{\circ} \mathrm{C}$ until use.

Phospholipid classes were quantified using a modified colorimetric microphosphorus assay (6). To each tube, $1 \mathrm{ml}$ of perchloric acid (Caledon, Georgetown, ON, Canada) was added and the mixture was heated to $130^{\circ} \mathrm{C}$ for $2 \mathrm{~h}$. The mixture was cooled to room temperature on ice and $7 \mathrm{ml}$ of distilled water, $1.5 \mathrm{ml}$ of ammonium molybdate $(2.5 \%$ [wt/vol]), and $0.2 \mathrm{ml}$ of Fiske and Subbarrow reagent (Sigma) were added to each tube. The tubes were placed in boiling water for $7 \mathrm{~min}$, then allowed to cool for $20 \mathrm{~min}$ on ice. Samples were analyzed at $\lambda 830$ on a UV-visible spectrophotometer (Varian, Palo Alto, CA). Calibration curves were obtained using potassium phosphate monobasic (BioShop, Burlington, ON, Canada) as a standard.

Phospholipid FA analysis. FA methyl esters (FAME) were prepared by transesterification using $2 \mathrm{ml}$ of $\mathrm{BF}_{3}$-methanol (14\%) for each sample and heating to $70^{\circ} \mathrm{C}$ for $60 \mathrm{~min}$. Samples were cooled on ice, diluted with $2 \mathrm{ml}$ of water, and extracted three times with $2 \mathrm{ml}$ of hexane. The hexane fractions were combined and FAME were analyzed on an Agilent 6890 Series gas chromatograph coupled with an Agilent 5973 quadropole mass spectrometer using a ZB-5 capillary column ( $30 \mathrm{~m}$ by $0.25 \mathrm{~mm}$ i.d. by $0.25 \mu \mathrm{m} ; 5 \%$ phenyl and $95 \%$ dimethyl-polysiloxane) in splitless mode. The temperature program began at $100^{\circ} \mathrm{C}$ and was increased by $20^{\circ} \mathrm{C} \mathrm{min}{ }^{-1}$ to $200^{\circ} \mathrm{C}$, held for $5 \mathrm{~min}$, increased by $10^{\circ} \mathrm{C} \mathrm{m^{-1 }}$ to $240^{\circ} \mathrm{C}$, and held for $5 \mathrm{~min}$. FAME were identified by comparison with the retention times of authentic standards (Supelco, Bellefonte, PA) and analysis of mass spectrum (MS) fragmentation. Peaks were analyzed using ChemStation software.

Statistical analysis. Analysis of variance (ANOVA) was performed with the GLM procedure of the SAS system (28) and, when significant $(P<0.05)$, treatment means were compared using Fisher's protected least significant difference test $(\alpha$ level $=$ 
0.05). In the mycelial growth trials (MIC assays), there was no variability in MIC within each tested concentration-pathogen combination. ANOVA was not possible without variance and standard errors are not provided as they equal zero.

Data were further analyzed for correlations between the different lipid categories or compounds and microbial sensitivity to fengycin. Results are reported as correlation coefficients $(r)$ with associated $P$ values.

\section{RESULTS}

Evaluation of microbial sensitivity to fengycin. Growth curves indicated that fengycin did not show a typical doseresponse effect on mycelial growth. Indeed, mycelial inhibition was nonexistent at tested fengycin concentrations that were lower than the MIC of each microorganism. MICs for the tested microorganisms were $100,50,75$, and $33 \mu \mathrm{g} / \mathrm{ml}$ for $A$. solani, $B$. cinerea, $F$. sambucinum, and $P$. sulcatum, respectively.

Total lipid content. Analysis of the total lipid content found $P$. sulcatum to have significantly higher intrinsic lipid content (fivefold higher) than $B$. cinerea (Table 1 ). A. solani and $F$. sambucinum had statistically similar lipid content (average 9\%), which was not significantly different from the other microorganisms. The percentage of neutral lipids was significantly higher in A. solani than neutral lipids in $B$. cinerea (Table 1 ). F. sambucinum and $P$. sulcatum had comparable percent neutral lipid content, which was not significantly different from the other microorganisms. Similar results were observed in the percentage of polar lipids. $B$. cinerea had a significantly higher percentage of polar lipids than $A$. solani while $F$. sambucinum and $P$. sulcatum had intermediate polar lipid content (Table 1).

TABLE 1. Total lipid and ergosterol contents of Alternaria solani, Botrytis cinerea, Fusarium sambucinum, and Pythium sulcatum ${ }^{\mathrm{u}}$

\begin{tabular}{lcccc}
\hline Lipids & A. solani & B. cinerea & F. sambucinum & P. sulcatum \\
\hline Total lipids $^{\mathrm{v}}$ & $10.0 \mathrm{ab}$ & $2.6 \mathrm{~b}$ & $7.8 \mathrm{ab}$ & $15.2 \mathrm{a}$ \\
Neutral lipidsw $^{\mathrm{w}}$ & $84.3 \mathrm{a}$ & $45.8 \mathrm{~b}$ & $70.9 \mathrm{ab}$ & $55.6 \mathrm{ab}$ \\
Polar lipidss & $15.7 \mathrm{~b}$ & $54.2 \mathrm{a}$ & $29.1 \mathrm{ab}$ & $44.4 \mathrm{ab}$ \\
E:DW ratio $^{\mathrm{x}}$ & $5.3 \mathrm{a}$ & $0.6 \mathrm{~b}$ & $0.2 \mathrm{~b}$ & $0.0 \mathrm{c}$ \\
E:L ratio $^{\mathrm{y}}$ & $5.9 \mathrm{a}$ & $0.7 \mathrm{~b}$ & $0.6 \mathrm{~b}$ & $0.0 \mathrm{c}$ \\
E:P ratio $^{\mathrm{z}}$ & $1.8 \mathrm{a}$ & $0.1 \mathrm{~b}$ & $0.1 \mathrm{~b}$ & $0.0 \mathrm{c}$ \\
\hline
\end{tabular}

u Values in a row with a letter in common are not significantly different according to Fisher's protected least significant difference test $(\alpha$ level $=$ $0.05)$.

${ }^{\mathrm{v}}$ Percent lipids/dry weight.

${ }^{\text {w }}$ Percent neutral or polar lipids/total lipids.

x Ratio of ergosterol/dry weight.

y Ratio of ergosterol/total lipids.

${ }^{\mathrm{z}}$ Molar ratio of ergosterol/phospholipids $=($ ergosterol content $\times 396) /($ phospholipids $\times 725$ ).

TABLE 2. Correlation of lipid parameters with microbial tolerance to fengycin

\begin{tabular}{lcc}
\hline Lipid parameter & $\begin{array}{c}\text { Correlation } \\
\text { coefficient }(r)^{\mathrm{w}}\end{array}$ & $P$ value \\
\hline Ergosterol/dry weight ratio & 0.8171 & 0.0012 \\
Ergosterol/total lipids ratio & 0.8507 & 0.0005 \\
Ergosterol/phospholipids ratio $^{\mathrm{x}}$ & 0.8327 & 0.0008 \\
Anionic/zwitterionic phospholipids $_{\text {Degree of unsaturation }\left(\Delta / \text { mol }_{18}\right)^{\mathrm{y}}}$ & 0.6533 & 0.0212 \\
${\text { Degree of unsaturation }\left(\Delta / \mathrm{mol} \mathrm{total}^{\mathrm{z}}\right.}_{\text {Average acyl chain length }}^{-0.1233}$ & 0.7029 \\
& 0.1248 & 0.6991 \\
\end{tabular}

"Pearson's correlation coefficient.

${ }^{x}$ Molar ratio of ergosterol/phospholipids $=($ ergosterol content $\times 396) /($ phospholipids $\times 725)$.

${ }^{\text {y }} \Delta / \mathrm{mol} \mathrm{C}_{18}=[(1 \times 18: 1)+(2 \times 18: 2)+(3 \times 18: 3)] /$ total C 18 .

${ }^{\mathrm{z}} \Delta /$ mol total $=[(1 \times$ monoene $)+(2 \times$ diene $)+(3 \times$ triene $)+(4 \times$ tetraene $)+$ $(5 \times$ pentaene $)] / 100$.
Analysis of ergosterol content. In all cases, A. solani was found to have the highest ratio of ergosterol (Table 1) regardless of the basis of comparison (relative to biomass dry weight, total lipids, or phospholipids). Ergosterol content of $B$. cinerea and $F$. sambucinum was significantly lower than in A. solani (Table 1). Sterols were not detected in P. sulcatum (Table 1). Correlation analysis revealed a strong positive linear relationship $(r \geq 0.82$, $P \leq 0.001)$ between all three ergosterol content measurements and tolerance of microorganisms to fengycin (Table 2).

Analysis of phospholipid classes. The composition of phospholipids in the membranes of the tested organisms exhibited some variation. Both phosphatidic acid (PA) and phosphatidylglycerol (PG) had statistically similar content across all tested organisms (Table 3 ). The average amounts of PA and PG were $\approx 2$ and $36 \%$ of total polar lipids, respectively. Phosphatidylcholine (PC) was highest in A. solani and $F$. sambucinum $(\approx 36 \%)$. $P$. sulcatum had a significantly lower PC than $A$. solani and $F$. sambucinum, while $B$. cinerea contained the least amount of PC (Table 3).

The proportion of phosphatidylethanolamine (PE) exhibited the greatest variation among tested organisms (Table 3 ). $P$. sulcatum had the highest PE content of all tested organisms. B. cinerea had lower PE content, whereas A. solani and F. sambucinum had the lowest PE content. Phosphatidylserine (PS) and phosphatidylinositol (PI) co-migrated in the employed solvent system. A. solani, $B$. cinerea, and F. sambucinum had similar PS + PI content, whereas PS + PI content was significantly lower in P. sulcatum (Table 3). B. cinerea had a significantly higher proportion of cardiolipin then all other tested microbial strains. An unknown phospholipid was also identified in statistically similar proportions in both $A$. solani and $F$. sambucinum and was undetectable in B. cinerea and $P$. sulcatum (Table 3). F. sambucinum was found to have the largest anionic/zwitterionic (A/Z) phospholipid ratio while $P$. sulcatum had the lowest. A. solani and B. cinerea had statistically similar $A / Z$ ratios. $A / Z$ ratio showed a moderate positive linear relationship with microbial tolerance (Table 2).

Phospholipid FA profiles. Analysis of the FA profiles showed marked variability in relative percentage of individual FAs between microorganisms (Table 4). Palmitic (16:0), oleic (18:1 $\Delta 9$ ), and linoleic $(18: 2 \Delta 9,12)$ were the main FAs found, accounting for $58.8 \%$ (P. sulcatum) to $90.9 \%$ (A. solani) of total FAs (Table 4) in each microorganism. Among these major FAs, 16:0 content was highest in $B$. cinerea and $P$. sulcatum. $F$. sambucinum had lower 16:0 content than $P$. sulcatum and $A$. solani had lower 16:0 content than $B$. cinerea and $P$. sulcatum. The $18: 1$ content was similar in A. solani, F. sambucinum, and P. sulcatum $(\approx 16.5 \%)$.

TABLE 3. Phospholipid content (percentage of total polar lipids) of Alternaria solani, Botrytis cinerea, Fusarium sambucinum, and Pythium sulcatum ${ }^{\mathrm{v}}$

\begin{tabular}{lcccc}
\hline Phospholipid $^{\mathrm{w}}$ & A. solani & B. cinerea & F. sambucinum & P. sulcatum \\
\hline PA & $2.7 \mathrm{a}$ & $2.0 \mathrm{a}$ & $0.8 \mathrm{a}$ & $2.7 \mathrm{a}$ \\
PC & $39.4 \mathrm{a}$ & $7.1 \mathrm{c}$ & $33.9 \mathrm{a}$ & $17.5 \mathrm{~b}$ \\
PE & $1.8 \mathrm{c}$ & $34.5 \mathrm{~b}$ & $2.0 \mathrm{c}$ & $41.6 \mathrm{a}$ \\
PG & $34.0 \mathrm{a}$ & $37.1 \mathrm{a}$ & $42.0 \mathrm{a}$ & $32.0 \mathrm{a}$ \\
PS+PI & $19.1 \mathrm{a}$ & $14.1 \mathrm{a}$ & $17.4 \mathrm{a}$ & $5.0 \mathrm{~b}$ \\
CL & $2.6 \mathrm{~b}$ & $5.2 \mathrm{a}$ & $2.7 \mathrm{~b}$ & $1.2 \mathrm{~b}$ \\
Unknown & $1.3 \mathrm{a}$ & - & $3.8 \mathrm{a}$ & - \\
Anionic & $58.6 \mathrm{a}$ & $58.4 \mathrm{a}$ & $63.6 \mathrm{a}$ & $40.9 \mathrm{~b}$ \\
Zwitterionicy $^{\mathrm{y}}$ & $41.4 \mathrm{~b}$ & $41.6 \mathrm{~b}$ & $36.4 \mathrm{~b}$ & $59.1 \mathrm{a}$ \\
A/Z & $1.4 \mathrm{~b}$ & $1.4 \mathrm{~b}$ & $1.8 \mathrm{a}$ & $0.7 \mathrm{c}$
\end{tabular}

$\mathrm{v}$ Values in a row with a letter in common are not significantly different according to Fisher's protected least significant difference test $(\alpha$ level $=$ $0.05) ;$ - indicates not detected.

${ }^{\mathrm{w}} \mathrm{PA}=$ phosphatidic acid, $\mathrm{PC}=$ phosphatidylcholine, $\mathrm{PE}=$ phosphatidylethanolamine, $\mathrm{PG}=$ phosphatidylglycerol, $\mathrm{PS}+\mathrm{PI}=$ phosphatidylserine + phosphatidylinositol, $\mathrm{CL}=$ cardiolipin.

$\mathrm{x}$ Anionic $=$ percent anionic phospholipids

y Zwitterionic $=$ percent $z$ witterionic phospholipids.

${ }^{\mathrm{z}} \mathrm{A} / \mathrm{Z}=$ ratio of anionic/zwitterionic phospholipids. 
The presence of 18:1 was not detected in B. cinerea. A. solani and $B$. cinerea showed the highest $18: 2$ content $(\approx 56 \%)$. F. sambucinum had a significantly lower 18:2 than $A$. solani and $B$. cinerea while $P$. sulcatum showed the lowest 18:0 content. Among other FAs, 12:0, 13:0, 14:1, 18:3, 20:1, 20:2, 20:3, 20:4, and 20:5 were only detected in P. sulcatum (Table 4). Of particular note, the highly unsaturated 20:4 and 20:5 were present in relatively high concentrations in $P$. sulcatum compared with the other tested fungi (Table 4).

In order to better comprehend total unsaturation of the FAs, various percentages and ratios were calculated. Saturated FAs were highest in P. sulcatum. B. cinerea and F. sambucinum contained statistically lower saturated FA contents, whereas $A$. solani contained the lowest saturated FA content (Table 4). Monounsaturated FAs were similar in A. solani, F. sambucinum, and $P$. sulcatum $(\approx 20 \%)$ whereas $B$. cinerea had significantly lower monounsaturated FAs. Polyunsaturated FAs were highest in A. solani and $B$. cinerea $(\approx 56 \%)$. F. sambucinum contained significantly lower polyunsaturated FAs. $P$. sulcatum contained the least amount of polyunsaturated FAs. Overall, the total unsaturated FAs were highest in A. solani and lowest in P. sulcatum (Table 4). A significantly higher ratio of unsaturated to saturated FAs was found in A. solani (Table 4). The ratio of polyunsaturated to monounsaturated was significantly higher in $B$. cinerea than the other tested fungal strains by $\approx 10$-fold (Table 4 ). The degree of unsaturation of the $\mathrm{C}_{18} \mathrm{FA}$ was highest in $B$. cinerea whereas $F$. sambucinum and $P$. sulcatum had the lowest degree of $\mathrm{C}_{18} \mathrm{FA}$ unsaturation (Table 4). When degree of unsaturation of all detected FA $(\Delta / \mathrm{mol}$ total) was analyzed, there were no significant differences among all the microorganisms (Table 4). The average length of the phospholipid fatty acyl chains was significantly higher in $A$. solani and $F$. sambucinum than in B. cinerea and $P$. sulcatum. Correlation analysis showed a nonsignificant correlation between the degrees of unsaturation (of $\mathrm{C}_{18} \mathrm{FA}$ or total FA) and tolerance to fengycin (Table 2). Conversely, correlation analysis showed a strong positive linear relationship between fatty acyl chain length and fengycin tolerance (Table 2).

\section{DISCUSSION}

Among biocontrol agents, those producing antimicrobial compounds with modes of action thought to affect fungal biological membranes are of great interest because they may reduce the onset of genetic resistance in plant pathogens (19). A fungus may become resistant through spontaneous or induced genetic mutation, or through the acquisition of resistance genes from other species, leading to the entire bypassing of the affected pathway (22). Because there is an evolutionary limit placed on adapting or redesigning biomembranes, it is hypothesized that microorganisms sensitive to these membrane-targeting antimicrobials will tend to remain sensitive (2). More generally, the fungal membrane is responsible for maintaining cell order, integrity, and essential functions, and is imperative to the survival of a fungus (2,11, 12,35). The dynamic of the membrane and its lipid composition play a crucial role in its interactions with the environment and with many membrane-associated proteins $(2,7)$. Although the general membrane structure is based on a phospholipid backbone, ergosterol is the most notable sterol in the fungal membrane (33), which differentiates fungal membranes from other eukaryotes, including plants and animals. Most importantly, the general lipid composition of fungal and related membranes varies among taxonomically different species (33).

Among antimicrobial compounds with membrane-targeting activity, fengycin A, produced by various B. subtilis strains, including CU12, is of interest because of its high antifungal activity and low hemolytic activity $(15,32)$. In this study, we analyzed intrinsic sterol content, phospholipid composition (polar head moieties), and FA profiles of various fungal and fungus-like plant pathogens in an attempt to elucidate the biochemical determinants of microbial sensitivity to fengycin.

MIC analysis indicated that the most tolerant microorganism tested was $A$. solani, followed in decreasing order by $F$. sambucinum, B. cinerea, and finally $P$. sulcatum. Of particular note was the lack of a dose-dependent response in the inhibitory activity of fengycin. Previous work has also described this phenomenon and has characterized fengycin activity on biomembranes as an all-ornone activity (26).

Sterol analysis showed that ergosterol content correlated strongly with relative sensitivity of the tested microorganisms to fengycin. Indeed, the most tolerant fungus (A. solani) contained higher ergosterol content than the more sensitive fungi ( $F$. sambucinum and $B$. cinerea). The oomycete $P$. sulcatum was included in this study because it does not produce sterols, which correlated well with its higher sensitivity to fengycin. Although sterols (cholesterol in particular) may fluidize highly rigid membranes (13), ergosterol present in less rigid, more fluid membranes, such as those of actively growing fungal cells (3), would have the reverse effect. Indeed, ergosterol is known to buffer stress induced changes in membrane fluidity (8), which may explain its role in fengycin tolerance. Therefore, microorganisms containing little or no sterols would be more susceptible to fengycin-membrane interactions, leading to a decrease in viability, whereas those with a larger proportion of sterols would be more capable of buffering stress induced changes. A previous study (3) found that the fungi Idriella bolleyi and Pseudozyma

TABLE 4. Fatty acid (FA) profiles of polar extracts from Alternaria solani, Botrytis cinerea, Fusarium sambucinum, and Pythium sulcatum ${ }^{\mathrm{u}}$

\begin{tabular}{|c|c|c|c|c|}
\hline FA & A. solani & B. cinerea & F. sambucinum & P. sulcatum \\
\hline $12: 0$ & - & - & - & 0.8 \\
\hline 13:0 & - & - & - & 0.0 \\
\hline $14: 0$ & - & $0.4 \mathrm{~b}$ & $0.6 \mathrm{~b}$ & $12.6 \mathrm{a}$ \\
\hline $14: 1 \Delta 9$ & - & - & - & 0.2 \\
\hline $15: 0$ & - & $0.2 \mathrm{a}$ & $0.2 \mathrm{a}$ & $0.1 \mathrm{a}$ \\
\hline $16: 0$ & $17.6 \mathrm{c}$ & $28.6 \mathrm{ab}$ & $23.0 \mathrm{bc}$ & $29.7 \mathrm{a}$ \\
\hline $16: 1 \Delta 9$ & $1.4 \mathrm{~b}$ & $2.2 \mathrm{~b}$ & $2.0 \mathrm{~b}$ & $7.5 \mathrm{a}$ \\
\hline $17: 0$ & - & $0.1 \mathrm{a}$ & $0.2 \mathrm{a}$ & $0.1 \mathrm{a}$ \\
\hline $17: 1 \Delta 10$ & - & 0.3 & - & - \\
\hline $18: 0$ & $3.8 \mathrm{~b}$ & $2.3 \mathrm{c}$ & $7.5 \mathrm{a}$ & $0.9 \mathrm{~d}$ \\
\hline $18: 1 \Delta 9$ & $19.8 \mathrm{a}$ & - & $17.8 \mathrm{a}$ & $11.9 \mathrm{a}$ \\
\hline $18: 2 \Delta 9,12$ & $53.5 \mathrm{a}$ & $59.1 \mathrm{a}$ & $44.8 \mathrm{~b}$ & $17.2 \mathrm{c}$ \\
\hline $20: 0$ & - & - & $0.2 \mathrm{a}$ & $0.1 \mathrm{a}$ \\
\hline 18: $3 \Delta 6,9,12$ & - & - & - & 1.2 \\
\hline $20: 1 \Delta 11$ & - & - & - & 0.3 \\
\hline $20: 2 \Delta 11,14$ & - & - & - & 0.2 \\
\hline $22: 0$ & - & $0.2 \mathrm{a}$ & $0.2 \mathrm{a}$ & $0.0 \mathrm{a}$ \\
\hline $20: 3 \Delta 8,11,14$ & - & - & - & 0.8 \\
\hline $22: 1 \Delta 9$ & - & - & - & 0.3 \\
\hline $20: 4 \Delta 5,8,11,14$ & - & - & - & 3.6 \\
\hline $20: 5 \Delta 5,8,11,14,17$ & - & - & - & 8.6 \\
\hline Saturated & $21.3 \mathrm{c}$ & $31.9 \mathrm{~b}$ & $31.7 \mathrm{~b}$ & $44.3 \mathrm{a}$ \\
\hline Monounsaturated & $20.8 \mathrm{a}$ & $2.4 \mathrm{~b}$ & $19.7 \mathrm{a}$ & $20.0 \mathrm{a}$ \\
\hline Polyunsaturated & $53.5 \mathrm{a}$ & $59.1 \mathrm{a}$ & $44.8 \mathrm{~b}$ & $31.7 \mathrm{c}$ \\
\hline Total unsaturated & $74.2 \mathrm{a}$ & $61.6 \mathrm{~b}$ & $64.6 \mathrm{~b}$ & $51.9 \mathrm{c}$ \\
\hline $\mathrm{U}: \mathrm{S}$ ratio $^{\mathrm{v}}$ & $3.6 \mathrm{a}$ & $2.0 \mathrm{~b}$ & $2.0 \mathrm{~b}$ & $1.2 \mathrm{~b}$ \\
\hline $\mathrm{P}: \mathrm{M}$ ratio $^{\mathrm{w}}$ & $2.6 \mathrm{~b}$ & $25.3 \mathrm{a}$ & $2.3 \mathrm{~b}$ & $1.7 \mathrm{~b}$ \\
\hline$\Delta / \mathrm{mol} \mathrm{C}_{18}{ }^{\mathrm{x}}$ & $1.7 \mathrm{~b}$ & $1.9 \mathrm{a}$ & $1.5 \mathrm{c}$ & $1.6 \mathrm{bc}$ \\
\hline$\Delta / \mathrm{mol}^{\text {total }}{ }^{\mathrm{y}}$ & $1.3 \mathrm{a}$ & $1.3 \mathrm{a}$ & $1.1 \mathrm{a}$ & $1.2 \mathrm{a}$ \\
\hline Average AC length ${ }^{\mathrm{z}}$ & $17.5 \mathrm{a}$ & $17.1 \mathrm{~b}$ & $17.4 \mathrm{a}$ & $16.9 \mathrm{~b}$ \\
\hline
\end{tabular}

" Fatty acid profiles are presented in percent area (percentage of total area). Values in a row with a letter in common are not significantly different according to Fisher's protected least significant difference test $(\alpha$ level $=$ $0.05) ;-$ indicates not detected.

${ }^{v}$ Ratio of unsaturated/saturated FA.

${ }^{\mathrm{w}}$ Ratio of polyunsaturated/monounsaturated FA.

x Degree of unsaturation: $\Delta / \mathrm{mol} \mathrm{C}_{18}=[(1 \times 18: 1)+(2 \times 18: 2)+(3 \times 18: 3)] /$ total $\mathrm{C}_{18}$.

y Degree of unsaturation: $\Delta / \mathrm{mol}$ total $=[(1 \times$ monoene $)+(2 \times$ diene $)+(3 \times$ triene $)+(4 \times$ tetraene $)+(5 \times$ pentaene $)] / 100$.

z $\mathrm{AC}=$ acyl chain. 
rugulosa had significantly higher ergosterol contents than all other fungi tested and were the most tolerant to an antifungal compound, cis-9-heptadecenoic acid, known to interact with fungal membranes and cause an elevation in membrane fluidity.

The overall amphipathic nature of glycerophospholipids is the foundation of membranes (30). Characteristics of individual phospholipids such as charge, head groups, and structure are known to vary between organisms and may alter membrane characteristics (16). There was little to no correlation between the individual phospholipid contents and sensitivity to fengycin; however, the ratio of anionic (acidic, negatively charged) to zwitterionic (neutral) phospholipids did correlate moderately with fengycin sensitivity. Results showed that the highly sensitive $P$. sulcatum possessed a generally more neutral composition of phospholipids, whereas the more resistant $F$. sambucinum possessed highly anionic phospholipids. This may indicate that fengycin preferentially interacts with zwitterionic rather than anionic lipids. Fengycin exhibits two negative charges (glutamic acid residues) and only one positive charge (ornithine residue), making it anionic in nature and reducing its miscibility with the phospholipid head groups $(12,14)$. The lipid tail of fengycin inserts readily into the membrane at physiological $\mathrm{pH}$ but the peptide moiety would remain outside the membrane (12). Other work has reported that the presence of negative charges on fengycin would result in electrostatic repulsion from the phospholipid head groups in the membrane $(14,21)$. Therefore, our results may indicate that the more anionic phospholipids in the more tolerant fungi reduce fengycin interactions with the membrane through increased electrostatic repulsion.

It has been found that FA composition and unsaturation in polar lipids can alter membrane fluidity as an adaptive response to temperature fluctuations or other stressors (3). The main FAs found in this study were palmitic (16:0), oleic (18:1 $\Delta 9)$, and linoleic $(18: 2 \Delta 9,12)$ acids. Similar studies on the FA profile of other fungi (Pleurotus ostreatus and P. cornucopiae) yielded similar results (27). Individual FA contents did not correlate well with microbial sensitivity. However, it should be noted that the highly unsaturated arachidonic (20:4) and eicosapentaenoic (20:5) acid were only detected in Pythium sulcatum and at relatively high concentrations, which might explain its higher sensitivity to fengycin. Previous work had also showed that oomycetes such as Pythium and Phytophthora spp. are generally regarded as sensitive to fengycin $(25,32)$. In addition, oomycetes are known to be among the few plant pathogens (in addition to the primitive Zygomycete fungi) to abundantly produce arachidonic and eicosapentaenoic acids (10,29), whereas higher fungi (e.g., Ascomycetes) typically do not contain these highly unsaturated long-chained FAs (5). Elevated FA unsaturation is known to increase membrane fluidity, which may adversely affect membrane order in the presence of an additional membrane-affecting compound (7). However, although unsaturation of specific FAs may indicate high membrane fluidity, the degrees of unsaturation over the major FA $\left(\Delta / \mathrm{mol} \mathrm{C}_{18}\right)$ or all FA present $(\Delta / \mathrm{mol}$ total $)$ is a more complete indicator of membrane fluidity. Of particular note, the average number of unsaturations over all FA $(\Delta / \mathrm{mol}$ total) indicated that all fungi had equivalent mean unsaturation per moiety $(\approx 1.2$ unsaturations per FA on average). The lack of variability in the degree of unsaturation in these results does not allow for conclusions on the implication of phospholipid FA unsaturation on microbial sensitivity to fengycin. Conversely, the average length of the fatty acyl chains correlated strongly with fengycin sensitivity. Indeed, microorganisms with shorter acyl chain lengths (B. cinerea and $P$. sulcatum) were more sensitive to fengycin. The shorter chain length would indicate a more fluid membrane. Previous work has shown that increased membrane fluidity would account for easier fengycin insertion into the membrane (12), which could explain its higher activity in membranes in a higher state of fluidity.
Overall, fungal sensitivity to fengycin appears to be related mainly to low quantities of sterols. Fengycin is known to act in an all-or-none type of action (26) and the buffering action of sterols may play a crucial role in the tolerance of a given organism (3). Another nonnegligible factor in microbial sensitivity may be a high quantity of zwitterionic phospholipids. The negatively charged fengycin may interact more easily with zwitterionic (neutral) phospholipids rather than anionic phospholipids $(14,21)$. Finally, the fluidity of the membrane caused by a shorter chain length may facilitate fengycin insertion in the membranes (12). Results obtained provide new insight into the biochemical determinants of fengycin's mechanisms of action. Future work will ascertain localization, co-localization, segregation, and aggregation (i.e., possible interactions) of fengycin with the lipid components in biomembranes.

\section{ACKNOWLEDGMENTS}

This work was supported by the Natural Sciences and Engineering Council (NSERC) of Canada. We thank J. D. Miller for use of gas chromatography and liquid chromatography mass spectrometry and D. McMullin for technical assistance.

\section{LITERATURE CITED}

1. Akpa, E., Jacques, P., Wathelet, B., Paquot, M., Fuchs, R., Budzikiewicz, H., and Thonart, P. 2001. Influence of culture conditions on lipopeptide production by Bacillus subtilis. Appl. Biochem. Biotechnol. 91-93:551561.

2. Avis, T. J. 2007. Antifungal compounds that target fungal membranes: Applications in plant disease control. Can. J. Plant Pathol. 29:323-329.

3. Avis, T. J., and Bélanger, R. R. 2001. Specificity and mode of action of the antifungal fatty acid cis-9-heptadecenoic acid produced by Pseudozyma flocculosa. Appl. Environ. Microbiol. 67:956-960.

4. Avis, T. J., Martinez, C., and Tweddell, R. J. 2006. Effect of chlorine atmospheres on the development of rhizopus rot [Rhizopus stolonifer] and gray mold [Botrytis cinerea] on stored strawberry fruits. Can. J. Plant Pathol. 28:526-532.

5. Avis, T. J., Michaud, M., and Tweddell, R. J. 2007. Role of lipid composition and lipid peroxidation in the sensitivity of fungal plant pathogens to aluminum chloride and sodium metabisulfite. Appl. Environ. Microbiol. 73:2820-2824.

6. Bartlett, G. R. 1959. Phosphorus assay in column chromatography. J. Biol. Chem. 234:466-468.

7. Benyagoub, M., Willemot, C., and Bélanger R. R. 1996. Influence of subinhibitory dose of antifungal fatty acids from Sporothrix flocculosa on cellular lipid composition in fungi. Lipids 31:1077-1082.

8. Bloch, K. 1983. Sterol structure and membrane function. Crit. Rev. Biochem. 14:47-92.

9. Bojanowski, A., Avis, T. J., Pelletier, S., and Tweddell, R. J. 2013. Management of potato dry rot. Postharvest Biol. Technol. 84:99-109.

10. Bostock, R. M, Savchenko, T., Lazarus, C., and Dehesh, K. 2011. Eicosapolyenoic acids: Novel MAMPs with reciprocal effect on oomycete-plant defense signaling networks. Plant Signal. Behav. 6:531533.

11. Deacon, J. W. 2006. Fungal Biology, 4th ed. Blackwell Publishing, Oxford, UK.

12. Deleu, M., Paquot, M., and Nylander, T. 2008. Effect of fengycin, a lipopeptide produced by Bacillus subtilis on model membranes. Biophys. J. 94:2667-2679.

13. Eeman, M., Francius, G., Dufrêne, Y. F., Nott, K., Paquot, M., and Deleu, M. 2009. Effect of cholesterol and fatty acids on the molecular interactions of fengycin with Stratum corneum mimicking lipid monolayers. Langmuir 25:3029-3039.

14. Eeman, M., Pegado, L., Dufrêne, Y. F., Paquot, M., and Deleu, M. 2009. Influence of environmental conditions on the interfacial organization of fengycin, a bioactive lipopeptide produced by Bacillus subtilis. J. Colloid. Interf. Sci. 329:253-264

15. Falardeau, J., Wise, C., Novitsky, L., and Avis, T. J. 2013. Ecological and mechanistic insights into the direct and indirect antimicrobial properties of Bacillus subtilis lipopeptides on plant pathogens. J. Chem. Ecol. 39:869-878.

16. Goyal, S., and Khuller, G. K. 1994. Structural and functional role of lipids in yeast and mycelia forms of Candida albicans. Lipids 29:793-797.

17. Hamdache, A., Lamarti, A., Aleu, J., and Collado, I. G. 2011. Non-peptide metabolites from the genus Bacillus. J. Nat. Prod. 74:893-899. 
18. Janisiewicz, W. J., and Korsten, L. 2002. Biological control of postharvest diseases of fruits. Annu. Rev. Phytopathol. 40:411-441.

19. Knight, S. C., Anthony, V. M., Brady, A. M., Greenland, A. J., Heaney, S. P., Murray, D. C., Powell, K. A., Schulz, M. A., Spinks, C. A., Worthington, P. A., and Youle, D. 1997. Rationale and perspectives on the development of fungicides. Annu. Rev. Phytopathol. 35:349-372.

20. Kolaei, E. A., Cenatus, C., Tweddell, R. J., and Avis, T. J. 2013. Antifungal activity of aluminium-containing salts against the development of carrot cavity spot and potato dry rot. Ann. Appl. Biol. 163:311-317.

21. Maget-Dana, R., and Ptak, M. 1995. Interactions of surfactin with membrane models. Biophys. J. 68:1937-1943.

22. McDonald, B. A., and Linde, C. 2002. Pathogen population genetics, evolutionary potential, and durable resistance. Annu. Rev. Phytopathol. 40:349-379.

23. Olanya, O. M., Honeycutt, C. W., Larkin, R. P., Griffin, T. S., He, Z., Halloran, J. M. 2009. The effect of cropping systems and irrigation management on development of potato early blight. J. Gen. Plant Pathol. 75:267-275

24. Ongena, M., and Jacques, P. 2008. Bacillus lipopeptides: Versatile weapons for plant disease biocontrol. Trends Microbiol. 16:115-125.

25. Ongena, M, Jacques, P., Touré, Y., Destain, J., Jabrane, A., and Thonart, P. 2005 Involvement of fengycin-type lipopeptides in the multifaceted biocontrol potential of Bacillus subtilis. Appl. Microbiol. Biotechnol. 69:29-38.

26. Patel, H., Tscheka, C., Edwards, K., Karlsson, G., and Heerklotz, H. 2011. All-or-none membrane permeabilization by fengycin-type lipopeptides from Bacillus subtilis QST713. Biochim. Biophys. Acta
1808:2000-2008.

27. Pedneault, K., Angers, P., Avis, T. J., Gosselin, A., and Tweddell, R. J. 2007. Fatty acid profiles of polar and non-polar lipids of Pleurotus ostreatus and P. cornucopiae var. 'citrino-pileatus' grown at different temperatures. Mycol. Res. 111:1228-1234.

28. SAS Institute. 1999. SAS/STAT User's Guide, Version 8. SAS Institute Inc., Cary, NC.

29. Savchenko, T, Walley, J. W., Chehab, E. W., Xiao, Y., Kaspi, R., Pye, M. F., Mohamed, M. E., Lazarus, C. M., Bostock, R. M., and Dehesh, K. 2010. Arachidonic acid: An evolutionarily conserved signaling molecule modulates plant stress signaling networks. Plant Cell 22:3193-3205.

30. Simon, E. W. 1974. Phospholipids and plant membrane permeability. New Phytol. 73:377-420.

31. Thakore, Y. 2006. The biopesticide market for global agricultural use. Ind. Biotechnol. 2:194-208.

32. Vanittanakom, W., Loeffler, W., Koch, U., and Jung, J. 1986. Fengycin-a novel antifungal lipopeptide antibiotic produced by Bacillus subtilis F-293. J. Antibiot. 39:888-901.

33. Weete, J. D. 1974. Fungal Lipid Biochemistry, Distribution and Metabolism. Plenum Press, New York.

34. Wise, C., Novitsky, L., Tsopmo, A., and Avis, T. J. 2012. Production and antimicrobial activity of 3-hydroxypropionaldehyde from Bacillus subtilis strain CU12. J. Chem. Ecol. 38:1521-1527.

35. Xie, W., Kania-Korwel, I., Bummer, P. M., and Lehmler, H.-J. 2007. Effect of potassium perfluorooctanesulfonate, perfluorooctanoate and octanesulfonate on the phase transition of dipalmitoylphosphatidylcholine (DPPC) bilayers. Biochim. Biophys. Acta 1768:1299-1308. 